\title{
The Effect of Pyrolysis Temperature and Time of Polypropylene on Quality of Carbon Nanotube with Flame Synthesis Method
}

\author{
Praswasti P.D.K Wulan ${ }^{1, *}$, Juan Octavian Daniel Sidauruk ${ }^{2}$, and Juli Ayu Ningtyas ${ }^{2}$ \\ ${ }^{1}$ Department of Chemical Engineering, Faculty of Engineering, Universitas Indonesia, Kampus UI-Depok, Jawa Barat 16424, \\ Indonesia \\ ${ }^{2}$ Sustainable Energy Research Group, Department of Chemical Engineering, Faculty of Engineering, Universitas Indonesia, \\ Kampus UI-Depok, Jawa Barat 16424, Indonesia
}

\begin{abstract}
Variations of the pyrolysis temperature and time are carried out to obtain the correlation between those variables and the number of pyrolysis gases, as well as the yield and quality of produced CNT. PP is pyrolyzed at a temperature range of $525-600^{\circ} \mathrm{C}$ to produce pyrolizate gases. The flame synthesis method is used to convert PP plastic waste into CNT alongside with the use of wired mesh stainless steel type SS 316 as the substrate. The substrate is pre-treated by oxidative heat treatment at $800^{\circ} \mathrm{C}$ for 10 minutes before the synthesis to breach the outer chromium layer and make grains on the catalytic surface to enable CNT to grow. Pyrolizate gases are mixed with oxygen flowed from a venturi, so combustion reaction occurs. The combustion gas is flowed to the synthesis reactor to produce CNT at $800^{\circ} \mathrm{C}$. Characterization of produced CNT is carried out using XRD, GC-FID, and TEM. The highest yield is obtained at the pyrolysis temperature of $525^{\circ} \mathrm{C}$ for 45 minutes. While the optimal quality based on the structure, crystalline and particle size is achieved at the pyrolysis temperature of $525^{\circ} \mathrm{C}$ for 30 minutes which results in CNT with $23.81 \mathrm{~nm}$ of average crystallite size and $104.8 \mathrm{~nm}$ of particle size.
\end{abstract}

\section{Introduction}

In this era, many efforts have been set forth to reduce the production of polypropylene plastic waste which has been increasing by approximately t $15 \%$ per year (UN Environmental Program). Along with the technological advancement, polypropylene plastic can be utilized to compose nanomaterials. It is due to the relatively vast amount of carbon content, which is about $86.7 \%$, which makes it potential to be converted into nano-sized carbon with affordable operating cost. Carbon nanotube (CNT) is nanotechnology material which has the firm mechanical strength and excellent electrical conductivity so that it can be utilized for many advanced applications, such as adsorbent, catalyst, composite material, electronic devices, reactor layers, a coloring agent, and lubricants.

In the recent years, the production and development of CNT are stagnant because of the operating cost factor. Thus, one of the most effective and efficient ways to synthesize CNT is through the flame synthesis method in which oxygen will be flowed with particular flow rate into a system to expose the auto-ignition from produced pyrolizate gases, so it will produce $\mathrm{CO}$ compounds that will be precipitated on the surface of the catalytic substrate. Aside from the type of carbon source, the operating variables of pyrolysis are also essential. The temperature and time of pyrolysis are two fundamental and imperative variables that can influence the quantity and quality of produced $\mathrm{CNT} .{ }^{[2]}$

\section{Materials and Method}

\subsection{Pre-treatment of Polypropylene and Catalytic Substrate}

Ten grams of polypropylene plastic that has been cleaned previously then cut into $2 \times 2 \mathrm{~cm}$ size. The substrate of stainless steel 316 wired mesh is split into two pieces of $18 \times 12 \mathrm{~cm}$ with a diameter size of $4 \mathrm{~cm}$. The substrates are further pre-treated by acid etching (using isopropanol) and oxidative heat treatment in 800 ${ }^{\circ} \mathrm{C}$ for 10 minutes (Wijardono, 2016).

\subsection{Pyrolysis of Polypropylene}

\footnotetext{
Corresponding author: wulan@,che.ui.ac.id
} 
Polypropylene plastics are placed in a boat inside of the pyrolysis reactor. The temperature of pyrolysis is set to $525^{\circ} \mathrm{C}$, while the time of pyrolysis is varied into 30,45 , 60 , and 90 minutes. After that, the pyrolysis gases will be stored in a gas sampler for all trials. Next, the same procedure goes for the pyrolysis temperature of 550 and $600{ }^{\circ} \mathrm{C}$ by using other rolls of the catalytic substrate that have been pre-treated. The pyrolysis gases that have been stored for each trial will be further characterized using GC-FID to figure out the percentage of its content.

\subsection{CNT Synthesis and Characterization}

Two rolls of SS 316 wired mesh are placed into the synthesis reactor. Argon flows with a flow rate of 100 $\mathrm{ml} / \mathrm{min}$, and oxygen equal to $33.3 \mathrm{ml} / \mathrm{min}$. The furnace of synthesis reactor is set to reach $800{ }^{\circ} \mathrm{C}$ while the pyrolysis temperature is placed to its designated temperature $\left(525,550\right.$, or $\left.600{ }^{\circ} \mathrm{C}\right)$. After 1 hour of synthesis reaction occurs, the flow of oxygen is stopped, followed with shutting down the furnace of both reactors. Next, the yield of produced CNT is calculated and characterized using XRD PSA, and TEM.

\section{Results and Discussion}

The mole percentage of generated pyrolysis gases at 525 ${ }^{\circ} \mathrm{C}, 550{ }^{\circ} \mathrm{C}, 600{ }^{\circ} \mathrm{C}$ are presented in Table 1,2 , and 3.

\subsection{Pyrolysis Temperature at $525^{\circ} \mathrm{C}$}

Table 1. Mole Percentage of Pyrolysis Gases at $525^{\circ} \mathrm{C}$

\begin{tabular}{llllll}
\hline & & \multicolumn{4}{c}{ Normalized Mole Percentage (\%) } \\
\cline { 3 - 6 } Compone & Name & 30 & 45 & 60 & 90 \\
& & minute & minute & minute & minute \\
& & $\mathrm{s}$ & $\mathrm{s}$ & $\mathrm{s}$ & $\mathrm{s}$ \\
\hline $\mathrm{CH}_{4}$ & Methane & 99.77 & 96.63 & 95.56 & 76.32 \\
$\mathrm{C}_{2} \mathrm{H}_{6}$ & Ethane & 0.16 & 2.11 & 4.16 & 14.07 \\
$\mathrm{C}_{2} \mathrm{H}_{4}$ & Ethylene & 0.07 & 0.14 & 0.07 & 0.56 \\
$\mathrm{C}_{3} \mathrm{H}_{8}$ & Propane & - & 1.12 & 0.21 & 5.53 \\
$\mathrm{C}_{3} \mathrm{H}_{6}$ & Propylene & - & - & - & 0.57 \\
$\mathrm{C}_{4} \mathrm{H}_{10}$ & iso- & - & - & - & 1.34 \\
& Butane & & & & \\
$\mathrm{C}_{4} \mathrm{H}_{10}$ & n-Butane & - & - & - & 0.14 \\
$\mathrm{C}_{4} \mathrm{H}_{8}$ & isobutyle & - & - & - & 0.56 \\
& ne & & & & \\
$\mathrm{C}_{5} \mathrm{H}_{12}$ & i-Pentane & - & - & - & 0.91
\end{tabular}

\subsection{Pyrolysis Temperature at $550^{\circ} \mathrm{C}$}

Table 2. Mole Percentage of Pyrolysis Gases at $550{ }^{\circ} \mathrm{C}$

\begin{tabular}{llllll}
\hline & & \multicolumn{4}{c}{ Normalized Mole Percentage (\%) } \\
\cline { 3 - 6 } Component & Name & $\begin{array}{l}30 \\
\text { minute }\end{array}$ & $\begin{array}{l}45 \\
\text { minute }\end{array}$ & $\begin{array}{l}60 \\
\text { minute }\end{array}$ & $\begin{array}{l}\text { m0 } \\
\text { minute }\end{array}$ \\
& & $\mathrm{s}$ & $\mathrm{s}$ & $\mathrm{s}$ & $\mathrm{s}$ \\
\hline $\mathrm{CH}_{4}$ & Methane & 40.82 & 33.15 & 32.89 & 31.84 \\
$\mathrm{C}_{2} \mathrm{H}_{6}$ & Ethane & 9.75 & 8.41 & 9.52 & 5.80
\end{tabular}

\begin{tabular}{|c|c|c|c|c|c|}
\hline $\mathrm{C}_{2} \mathrm{H}_{4}$ & Ethylene & 7.42 & 6.48 & 16.10 & 16.74 \\
\hline $\mathrm{C}_{3} \mathrm{H}_{8}$ & Propane & 4.18 & 3.20 & 4.55 & 2.35 \\
\hline $\mathrm{C}_{3} \mathrm{H}_{6}$ & $\begin{array}{l}\text { Propylen } \\
\text { e }\end{array}$ & 21.79 & 30.76 & 21.12 & 28.32 \\
\hline $\mathrm{C}_{4} \mathrm{H}_{10}$ & $\begin{array}{l}\text { iso- } \\
\text { Butane }\end{array}$ & 1.52 & 0.84 & 1.71 & - \\
\hline $\mathrm{C}_{4} \mathrm{H}_{10}$ & n-Butane & - & - & - & - \\
\hline $\mathrm{C}_{4} \mathrm{H}_{8}$ & $\begin{array}{l}\text { Isobuthyl } \\
\text { ene }\end{array}$ & 13.65 & 16.07 & 12.98 & 14.95 \\
\hline $\mathrm{C}_{5} \mathrm{H}_{12}$ & i-Pentane & 0.88 & 1.09 & 1.13 & - \\
\hline
\end{tabular}

\subsection{Pyrolysis Temperature of $600{ }^{\circ} \mathrm{C}$}

Table 3. Mole Percentage of Pyrolysis Gases at $600{ }^{\circ} \mathrm{C}$

\begin{tabular}{lll}
\hline & & $\begin{array}{l}\text { Normalized } \\
\text { Percentage (\%) }\end{array}$ \\
\cline { 3 - 3 } Component & Name & 9.54 \\
& & 7.11 \\
\hline $\mathrm{CH}_{4}$ & Methane & 7.26 \\
$\mathrm{C}_{2} \mathrm{H}_{6}$ & Ethane & 8.01 \\
$\mathrm{C}_{2} \mathrm{H}_{4}$ & Ethylene & 10.30 \\
$\mathrm{C}_{3} \mathrm{H}_{8}$ & Propane & 13.38 \\
$\mathrm{C}_{3} \mathrm{H}_{6}$ & Propylene & 5.29 \\
$\mathrm{C}_{4} \mathrm{H}_{10}$ & iso-Butane & 34.28 \\
$\mathrm{C}_{4} \mathrm{H}_{10}$ & n-Butane & 4.84 \\
$\mathrm{C}_{4} \mathrm{H}_{8}$ & isobutylene &
\end{tabular}

From Table 1, 2, and 3, it can be seen that the content of produced pyrolysis gas comprises various hydrocarbon compounds. At $525^{\circ} \mathrm{C}$, pyrolysis gases are predominantly methane, mainly when the time of pyrolysis is 30 minutes. The least methane content is obtained at 90 minutes. Alongside with the increase of pyrolysis time, there will be a reduction of mole percentage or amount of hydrocarbon gases due to the increased production of residue (char).

At $600^{\circ} \mathrm{C}$, pyrolysis gases are only produced until the time of pyrolysis reaches 30 minutes. It is due to to the fact that the thermal decomposition of polypropylene has reached the termination phase. This low amount of pyrolysis gas indicates that pyrolysis of the polymer at high temperature, particularly above $525^{\circ} \mathrm{C}$, can reduce the amount of pyrolysis product in the form of gas and liquid, while on the other hand, increasing the amount of char or residue ${ }^{[2]}$

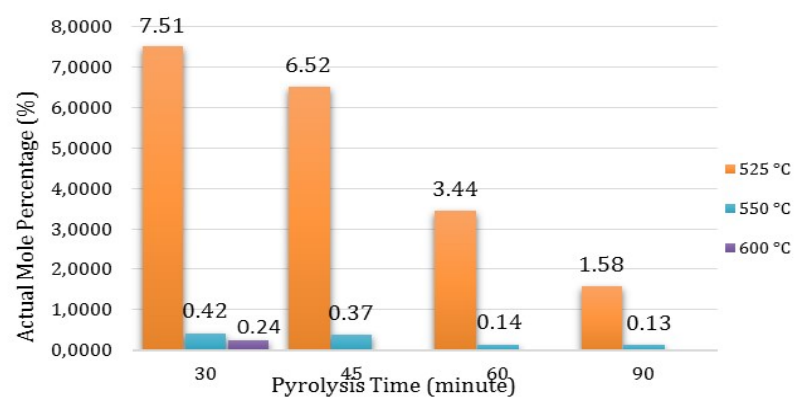

Fig. 1. Effect of Pyrolysis Temperature and Time toward the Actual Mole Percentage of Pyrolysis Gas 
Based on Figure 1, the actual mole percentage for all variations of pyrolysis temperature and time results in a relatively low amount, which is below $10 \%$. It is because the stored gases are predominantly gases that cannot be detected by GC-FID, such as argon, $\mathrm{CO}_{2}, \mathrm{CO}$, and $\mathrm{N}_{2}$.

On the other hand, Figure 1 indicates that based on the quantity, the actual mole percentage of hydrocarbon gases showcase reduced trend along with the increasing temperature and time of pyrolysis. Total mole percentage of hydrocarbon gases produced at $600{ }^{\circ} \mathrm{C}$ is considerably low, which is $0.24 \%$. According to the further increase of temperature, especially exceeds 550 or $600{ }^{\circ} \mathrm{C}$ will result in the reduced conversion of the pyrolysis product. This phenomenon showed the thermal degradation of secondary reaction would potentially produce residue or char. $^{[3]}$

\subsection{Synthesis of Carbon Nanotube}

Synthesis of CNT will be carried out with the following reaction mechanism as follows: ${ }^{[4]}[5]$

$$
\begin{aligned}
& \mathrm{C}_{x \mathrm{X}} \mathrm{H}_{y}+\mathrm{O}_{2} \rightarrow \mathrm{CO}+\mathrm{H}_{2} \mathrm{O} \\
& 2 \mathrm{CO}_{(g)} \rightarrow 2 \mathrm{C}_{(g)}+\mathrm{CO}_{2(g)} \\
& 2 \mathrm{CH}_{4}+3 \mathrm{O}_{2} \rightarrow 2 \mathrm{CO}+4 \mathrm{H}_{2} \mathrm{O}
\end{aligned}
$$

Table 4 shows that the percentage of methane gas is relatively dominant in the pyrolysis gas at a temperature of 525 and $550{ }^{\circ} \mathrm{C}$. Methane gas is one the most promising to be used as a feedstock for CNT synthesis due to its high ratio of hydrogen and carbon. ${ }^{[6]}$ Also, methane is reactive in the synthesis process of CNT with flame synthesis method. ${ }^{[5]}$ By using the suitable catalyst and operating condition, high purity methane can be productively applied to produce both of single wall and multi-wall CNT with uniform and good quality.

Table 4. Ratio of Methane and Oxygen in CNT Synthesis

\begin{tabular}{|c|c|c|c|c|}
\hline No & $\begin{array}{l}\text { The } \\
\text { temperature of } \\
\text { Pyrolysis }\left({ }^{\circ} \mathrm{C}\right)\end{array}$ & $\begin{array}{l}\text { Time of } \\
\text { Pyrolysis } \\
\text { (minutes) }\end{array}$ & $\begin{array}{l}\text { The ratio } \\
\text { of } \mathrm{CH}_{4} \text { : } \\
\mathrm{O}_{2}\end{array}$ & $\Phi$ \\
\hline 1 & \multirow{4}{*}{550} & 30 & $0.38: 1$ & 0.57 \\
\hline 2 & & 45 & $0.03: 1$ & 0.04 \\
\hline 3 & & 60 & $0.01: 1$ & 0.015 \\
\hline 4 & & 90 & 0.009:1 & 0.013 \\
\hline 5 & 600 & 30 & $0.005: 1$ & 0.007 \\
\hline
\end{tabular}

\begin{tabular}{lllll}
\hline No & $\begin{array}{l}\text { The } \\
\text { temperature of } \\
\text { Pyrolysis }\left({ }^{\circ} \mathrm{C}\right)\end{array}$ & $\begin{array}{l}\text { Time of } \\
\text { Pyrolysis } \\
\text { (minutes) }\end{array}$ & $\begin{array}{l}\text { The } \\
\text { ratio of } \\
\mathrm{CH}_{4}: \mathrm{O}_{2}\end{array}$ & $\Phi$ \\
\hline 1 & & 30 & $1.67: 1$ & 2.49 \\
2 & & 45 & $1.40: 1$ & 2.09 \\
3 & 525 & 60 & $0.73: 1$ & 1.09 \\
4 & & 90 & $0.27: 1$ & 0.40
\end{tabular}

Table 5. Ratio of Methane and Oxygen in CNT Synthesis
Table 4 showed the mole ratio of produced hydrocarbon gas toward the mole of oxygen for CNT synthesis shows a relatively linear reduction. Variable $\Phi$ is the comparison between the experimental ratio (hydrocarbon compared to oxygen) and the stoichiometric ratio (hydrocarbon compared to oxygen) based on the Equation 3.

The reduced value of $\Phi$ tends to result in the reduced amount of carbon monoxide as the product of synthesis reaction (based on the Equation 1). CO is a produced compound of partial oxidation of flame synthesis that can decompose into carbon and precipitate on the catalytic substrate medium in compliance to the Boudouard reaction on Equation 2. Thus, if the value of $\Phi$ decreases, so it potentially reduces the yield of produced CNT.

Table 6. Yield of produced CNT

\begin{tabular}{llll}
\hline $\begin{array}{l}\text { The } \\
\text { temperature } \\
\text { of Pyrolysis } \\
\left({ }^{\circ} \mathrm{C}\right)\end{array}$ & $\begin{array}{l}\text { Time of } \\
\text { Pyrolysis } \\
\text { (minute) }\end{array}$ & $\begin{array}{l}\text { The yield } \\
\text { of CNT } \\
\text { (gram) }\end{array}$ & $\begin{array}{l}\text { PP } \\
\text { Conversion } \\
(\%)\end{array}$ \\
\hline & 30 & 4.3047 & 43.047 \\
525 & 45 & 5.4048 & 54.048 \\
& 60 & 2.5694 & 25.694 \\
& 90 & 0.6934 & 6.934 \\
550 & 30 & 0.9716 & 9.716 \\
& 45 & 0.2172 & 2.172 \\
600 & 60 & 0.1635 & 1.635 \\
& 90 & 0.0922 & 0.922 \\
& 30 & 0.0079 & 0.079
\end{tabular}

Based on Table 5, the highest yield obtained at the $525{ }^{\circ} \mathrm{C}$ for 45 minutes, which equals to 5.4048 grams. Subsequently, the second highest yield is received at 525 ${ }^{\circ} \mathrm{C}$ for 30 minutes, which produces 4.3047 grams of CNT. In regards to the result of pyrolysis gas using instrument GC-FID, it can be seen that at both variations of temperature and time of pyrolysis, there has been the relatively high amount of paraffin (lower chain hydrocarbon, $\mathrm{C}_{1}-\mathrm{C}_{4}$ ). On the other hand, the lowest yield was obtained from pyrolysis gases obtained at 600 ${ }^{\circ} \mathrm{C}$ for 30 minutes.

Table 7. Average Crystalline and Particle Diameter of CNT

\begin{tabular}{lllll}
\hline & $\begin{array}{l}\text { The } \\
\text { temperature } \\
\text { of } \\
\text { Pymplysis } \\
\left({ }^{\circ} \mathrm{C}\right)\end{array}$ & $\begin{array}{l}\text { Time of } \\
\text { Pyrolysis } \\
\text { (minute) }\end{array}$ & $\begin{array}{l}\text { Average } \\
\text { Crystalline } \\
\text { Diameter } \\
\text { of CNT } \\
(\mathrm{nm})\end{array}$ & $\begin{array}{l}\text { Particle } \\
\text { Diameter } \\
\text { of CNT } \\
(\mathrm{nm})\end{array}$ \\
\hline 1 & & 30 & 23,81 & 104.8 \\
2 & 525 & 45 & 47,62 & 146.0 \\
3 & & 60 & 53,37 & 151.4
\end{tabular}


4

5

6

7

8

$\begin{array}{rlll} & 90 & 55,55 & 299.0 \\ 550 & 30 & 24,92 & 243.1 \\ & 45 & 27,79 & 252.3 \\ & 60 & 55,15 & 276.7 \\ & 90 & 68,75 & 280.6\end{array}$

The XRD characterization showed that there are several impurities, such as $\mathrm{Fe}_{2} \mathrm{O}_{3}, \mathrm{Fe}_{3} \mathrm{O}_{4}, \mathrm{Fe}_{3} \mathrm{C}$ and amorphous carbon. $\mathrm{Fe}_{2} \mathrm{O}_{3}, \mathrm{Fe}_{3} \mathrm{O}_{4}$, and $\mathrm{Fe}_{3} \mathrm{C}$ were formed because of the interaction between $\mathrm{Fe}$ of the substrate and oxygen at high temperature. The soot formation causes the formation of amorphous carbon on the substrate at the termination phase of CNT growth. ${ }^{[7]}$ Average crystalline and the particle diameter of CNT are presented in Table 6, as follows:

The average crystalline diameter of CNT is closely related to the value of $\Phi$ in Table 4 . The reduction of $\Phi$ does not only affect the reduced amount of $\mathrm{CO}$ but also result in the reduced yield of carbon that is deposited on the catalytic substrate medium and will influence the quality of produced CNT.

Based on the characterization of CNT particle diameter, it is obtained that the diameter ranges around $104.8-280.6 \mathrm{~nm}$. As such, sample 1, 2, and 3 have met the specification of multiwall CNT that ranges from 10$200 \mathrm{~nm}$.
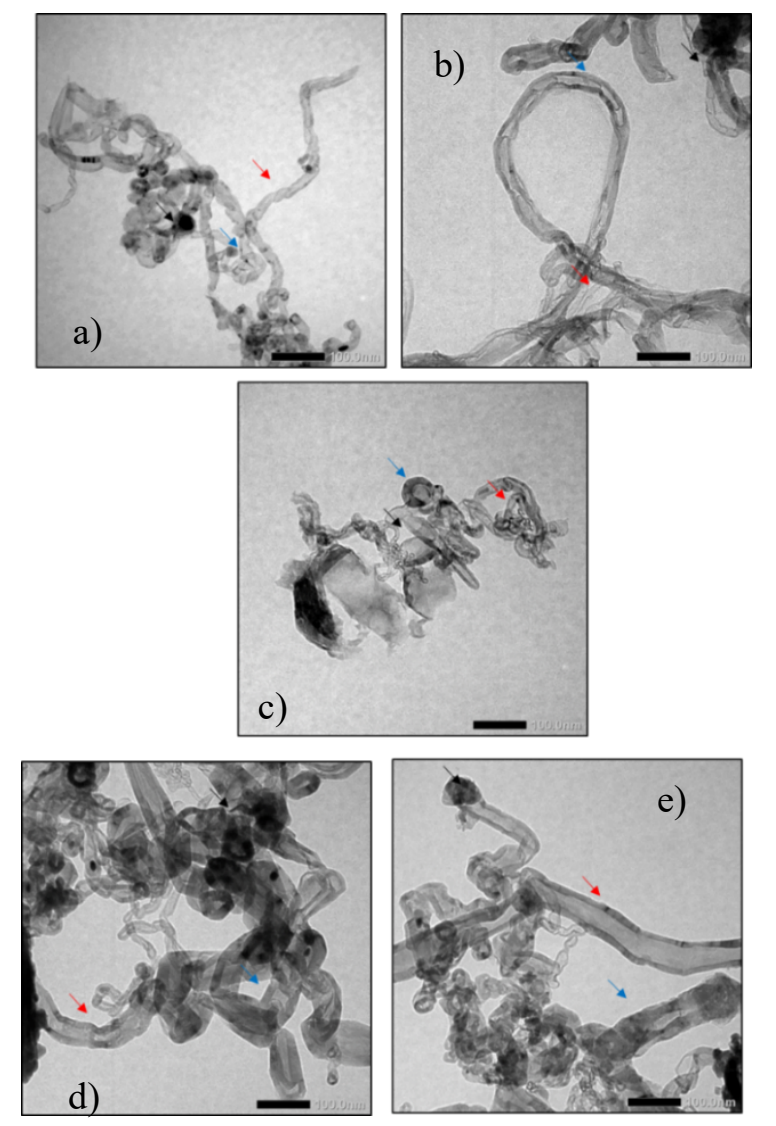

Fig. 2. TEM Image of (a) Sample 1; (b) Sample 2; (c) Sample 4; (d) Sample 5; (e) Sample 8
Figure 3(a) showed CNT started to form nano-sized walls continuously, but there are still many buckling phenomena. Produced CNT also formed a bent CNT. The bending phenomenon occurs as a result of a topological flow between the pentagon and heptagon ring at the carbon atoms or mechanical deformation from of the nanotube due to the bending stress because of the interaction with the adjacent nanotube, or even narrow space alongside with the growth of CNT. Even though many catalyst particles are penetrating to the CNT body, but overall, the CNT sample is dominated by the relatively big amount of impurity.

Based on Figure 3(b), the CNT growth has been started to form the smooth fibers like multiwall CNT (shown with the red arrow), but bamboo shaped CNT still dominates it. Bamboo-shape CNT is a cut coneshaped graphene layer. ${ }^{[8]}$ Based on the TEM characterization, it showed that the CNT has been deformed and lead to the buckling growth. This phenomenon is a condition when then CNT does not grow continuously due to the interaction between substrate and CNT or even between one CNT and another on the agglomeration process ${ }^{[9]}$ While CNT starts to grow, the morphology of catalyst starts to change and cause the catalyst to stretch and form small clusters. Alongside with the growth of CNT, CNT that can grow can crash or buckle with other CNTs that can cause the deformation on the CNT surface. Before reaching the termination phase, $\mathrm{CNT}$ will always find a space to grow, so, several parts bend permanently and will result in buckling growth. ${ }^{[10]}$

On Figure 3(c), it is seen that the produced CNT is still mainly comprised of many impurities, such as carbides, amorphous carbon, $\mathrm{Fe}_{2} \mathrm{O}_{3}$, and $\mathrm{Fe}_{3} \mathrm{O}_{4}$ that originated from the catalytic substrate surface. Those impurities penetrate into the body of CNT and inhibit the growth of layers inside the nanotube of CNT. The existence of those impurities is validated with the detected peak of $\mathrm{Fe}_{2} \mathrm{O}_{3} \quad \mathrm{Fe}_{3} \mathrm{O}_{4}$, and $\mathrm{Fe}_{3} \mathrm{C}$ on the chromatogram of XRD characterization. The blue and black arrow also points to the formation of relatively big carbon nano-onions and carbon nanofibre. At the end of CNT, many impurities have been formed from the catalyst layer. This leads to the low quality of produced CNT and cannot be utilized for many applications that need the excellent electrical conductivity or mechanical strength.

While in Figure 3(d), the produced carbon nanotube has been dominated by the significant amount of impurities but has formed bent and buckling multiwall layers of CNT. Black arrow shows when the parts of the catalyst penetrated into the CNT and caused the growth to be not optimum. This phenomenon is created by the catalysts between two adjacent nanotubes collide and enlarge the contact area, so it further inhibits the formation process of layer and wall of CNT.

Based on Figure 3(e), the multiwall CNT starts to be formed with relatively big particle diameter (pointed by the red arrow). CNT still grows in buckling and continuous manner, even though it is disconnected in specific points. The black arrow shows the tips growth of 
CNT in which the catalyst particle is lifted up to the end of CNT particle. In regards to the type of formed CNT, it is still predominantly carbon nanofibre and other impurities such as carbides, $\mathrm{Fe}_{2} \mathrm{O}_{3}$, and $\mathrm{Fe}_{3} \mathrm{O}_{4}$ derived from the catalyst. The formation of impurities in the CNT is not only because of the threshing of catalytic substrate layers, but also because of three other driving factors, such as the reduction of value of $\Phi$, the increasing amount of heavier hydrocarbon, as well as the ratio of inert gas (argon) that has not been optimum. As such, it causes the rising temperature in the synthesis area of CNT and further lead to the non-uniform CNT complemented by the formation of amorphous carbon and soot.

\section{Conclusions}

The highest yields of CNT are obtained at the pyrolysis temperature of $525{ }^{\circ} \mathrm{C}$ for 45 minutes and 30 minutes, which resulted in 5.4048 grams and 4.3047 grams of CNT respectively. Second of all the quality of CNT that most likely meet the specification of multiwall CNT (based on its structure, morphology, and diameter) is the sample obtained at the pyrolysis temperature of $525{ }^{\circ} \mathrm{C}$ and time of 30 minutes. As such, the most optimum time and temperature of pyrolysis to produce relatively high yield and good quality of $\mathrm{CNT}$ are at $525{ }^{\circ} \mathrm{C}$ for 30 minutes.

The authors acknowledge the financial support received from the Directorate of Research and Community Service Universitas Indonesia under PITTA Grant 2018 contract number: 2506/UN2.R3.1/HKP.05.00/2018. We are thankful, also, to Laboratory of Chemical and Resource Product Engineering (RPKA) Department of Chemical Engineering, Universitas Indonesia, Laboratory of Lemigas, and Laboratory of Fire and Safety Universitas Negeri Jakarta for the instruments characterization.

\section{References}

1. E Parparita. Gas Production by Steam Gasification of Polypropylene/Biomass Waste Composites in a Dual-Bed Reactor. J. of Waste Cycle of Springer 4, pp. 101-114. (2014).

2. S.V Papuga. Temperature and Time Influence on the Waste Plastics. J. of Thermal Sci. 20, No. 2 (2016), pp. 731-741. (2016).

3. Liu et al. Catalytic Pyrolysis of Polypropylene to Synthesize Carbon Nanotubes and Hydrogen Through a Two-Stage Pyrolysis. Polymer Degradation and Stability 96, pp 1711 - 1719. (2011).

4. J.P. Gore, and S, Anup. Flame Synthesis of Carbon Nanotubes. Thesis. Indiana: Purdue University. (2011).

5. W. Vander. Optimization of Flame Synthesis for Carbon Nanotubes Using Supported Catalyst. J. of Physical Chem.13, pp. 122-132. (2002)
6. P.P.D.K. Wulan and Y.D Lestari. The Effect of Oxidative Heat Treatment on the Preparation of Stainless steel 304 and 316 as the Effective Catalytic Substrate for Carbon Nanotube Gowth. IJTech Publication (2017)

7. P.P.D.K. Wulan and S.B. Wijardono, Finding an optimum period of oxidative heat treatment on SS 316 catalyst for nanocarbon production from LDPE plastic waste. Int. J. on Advanced Sci., Eng. and Information Tech., 7 (2), pp. 552-558. (2017).

8. Zhang, M. and Li, J. Carbon Nanotube in Different Shapes. Materials Today 12, no. 6. pp. 12-18. (2015)

9. Mishra, et al. Pyrolysis of Waste Polypropylene for the Synthesis of Carbon Nanotubes. J. of Analytical and Applied Pyrolysis pp. 91-98. (2012)

10. Zhuo, C. et al. Oxidative Heat Treatment of $316 \mathrm{~L}$ Stainless Steel for Effective Catalytic Growth of Carbon Nanotubes. Applied Surface Science, pp 1 -6. (2014). 